\title{
Development and Evaluation of Mechanized Fish Paste Maker
}

\author{
Michelle D. Enriquez, Christine Joy I. Ballo*
}

College of Engineering, Occidental Mindoro State College, Philippines

Received November 30, 2021; Revised January 17, 2022; Accepted February 3, 2022

\section{Cite This Paper in the following Citation Styles}

(a): [1] Michelle D. Enriquez, Christine Joy I. Ballo , "Development and Evaluation of Mechanized Fish Paste Maker," Food Science and Technology, Vol. 10, No. 1, pp. 9 - 16, 2022. DOI: 10.13189/fst.2022.100102.

(b): Michelle D. Enriquez, Christine Joy I. Ballo (2022). Development and Evaluation of Mechanized Fish Paste Maker. Food Science and Technology, 10(1), 9 - 16. DOI: 10.13189/fst.2022.100102.

Copyright $\mathrm{C} 2022$ by authors, all rights reserved. Authors agree that this article remains permanently open access under the terms of the Creative Commons Attribution License 4.0 International License

\begin{abstract}
The Philippines, being surrounded by water has an abundant source of fish; making fish processing one of the established industries in the country. Fish paste-making provides an opportunity to make the unsold fish useful and saleable. Traditionally, the method of fish paste making is manually processed as it involves the use of bare hands; hygiene, sanitation, and increasing labor cost hinder the profitability of the business. This study employed developmental research to produce a machine that can provide a solution to the fish paste industry. Since bare hands are mostly used during mixing, squeezing, and straining of salt and fish; the mechanized fish paste maker combines the mixing and straining process in one compartment to prevent the manual handling of raw materials. The developed machine was evaluated to determine the operation's performance based on functionality, durability, efficiency, and safety. The grand mean of 4.57 defined that the product met the intended purpose, had durable design and materials, was efficient and consistent in providing ease of operation and safe to use. The time and motion study further proved that the use of the machine lessens the production process by almost half of the normal duration and can guarantee an increase in the number of bottles produced. More importantly, the cost-benefit analysis showed that the machine is capable to increase the production benefits as it lessens the manual cost and other production costs.
\end{abstract}

Keywords Mechanized Fish Paste Maker, Time and Motion Study, Performance Efficiency, Cost-Benefit Analysis

\section{Introduction}

The Philippines, as an archipelagic country is gifted with rich fisheries and aquatic resources providing a vast opportunity for food and living. The fishing industry contributed 1.8 percent and 1.5 percent to the country's gross domestic product in 2014 and 2015 [1-2]. The fish processing industry offers valuable protein requirements and employment opportunities for many Filipinos. The proper utilization of fish products has led to the preservation process such as drying, salting, and smoking to maximize fish. Filipinos are popular for fish fermentation or the so-called fish sauce and fish paste [3]. Fermentation is one method of fish curing to develop a distinctive flavor in the final product [4]. Fish fermenting is the process of combining the salt and fish in considerable amounts and allowing it to ferment over some time to produce the fish paste or the fish sauce. Fish paste is a common ingredient and a famous delicacy highly sought by locals and tourists [5-6].

Fish paste or "fish paste" is a semi-liquid product obtained from the liquefaction of a mixture of fish and salt. This is widely used as a condiment but is also used as a protein food for the poorer section of the population especially in places far from the sea where fresh fish is seldom available [7]. The traditional method of fish fermentation entails manual mixing, squeezing, straining, and bottling and each stage requires space for the laborers to execute the process. The presence of extraneous materials and hygienic and sanitation issues are the common problems faced by fish processors. But the traditional process of fish paste making entails manual handling of raw materials from the mixing of salt and fish 
to the straining and bottling process. The variation in the labor cost and the hygienic and sanitation problems is the leading problem by most of the fish paste producers. Although traditional processing still represents a low-cost option for many small-scale producers, production loss in terms of wasted fish is at stake. This prompted the fish paste producers to seek improved technologies that are not expensive but can increase the quality and the efficiency of the process.

As mechanization is continuously introduced in the country, fish processors seek the attention of the local fabricators, government, and investors to help them increase the quality of the product and lessen the production cost. The fish paste squeezer [6] developed in Lingayen, Pangasinan, Philippines has a designed capacity of $24 \mathrm{~L}$ consisting of a perforated cylindrical bucket with paddle spins at 1700rpm which carries the fish substrate; a one-directional motor, $1 / 4 \mathrm{hp}$ capacity; the casing houses the bucket and the motor, and its accessories. The fish paste squeezer is supported by a food product cooperator and the user has satisfied the product cooperator. However, the developed prototype did not meet the requirements of the Pangasinan, Philippines fish paste processors and was further recommended for a higher capacity of the motor. A fish grinder developed in China can separate fish from fishbone, fish skin, the fish tendon to raise the fish use rate by saving manpower can grind and produce fish chum with a production capacity of $400-500 \mathrm{~kg} / \mathrm{h}$. The fish grinders incorporated a packaging system that facilitates the storage and dispersion of water keeping the process organized and clean [8]. While a sauce filling machine developed in Thailand used for fish canning manufacturing has a rotary conveyor that speeds up the mixing process. A refill storage tank is installed in the sauce filling machine decreasing the sauce loss filling in the canning industry [9]. While a canned food device for straining and draining liquids and juices from solid foods is known as a tuna squeezer effectively eliminates the risk of spilling the liquid on hands or countertops from the disc having spaced apart holes and a handle attached to the disc [10].

Occidental Mindoro, Philippines is abundant in water resources, making it one of the contributors of fresh fish in the market. The growing business of fish paste-making continues to prosper in the island province with the bulk of fishes harvested in the nearby water areas. Fish paste-making provides an opportunity to make the unsold fish useful and saleable. The traditional method of fish paste making which causes sanitation problems prompted the researchers to develop a machine that could provide a solution to the fish paste industry. This study aims to develop a Mechanized Fish Paste Maker purposely designed for the fish paste producers in the province. The researchers aim to produce a portable machine that combines the mixing, straining, and bottling process into one that can improve the quality of the fish paste product by lessening the manual handling of raw materials. Specifically, it aims to: test and evaluates the product in terms of functionality, durability, efficiency, and safety; determine the efficiency rating of the developed mechanized three-stage fish paste maker in terms of the time of mixing and straining process and number of a bottled fish paste produced, and perform time-motion analysis and cost-benefit analysis for the developed product against the traditional fish paste process.

\section{Materials and Methods}

\subsection{Fabrication of Mechanized Fish Paste Maker}

The study employed experimental study of engineering planning, design, development, and testing of mechanized fish paste maker. The process started from the planning stage, where all the materials are listed to carry out in the designing stage; existing technologies were studied and investigated. Then, the conceptualization of the design and composition of the prototype including materials, tools, and equipment needed, specifications and technical considerations, and the construction methods were scientifically selected. The actual construction process commenced with welding of the different parts of the product. After the initial set-up and assembly of the major parts, the developed product was operated to ensure how the system components work and observed to identify the durability and deficiencies. The final modification was done after the initial operation was observed.

\subsection{Product Description}

The developed mechanized fish paste maker combines the mixing, straining, and bottling process involved in fish paste production and aims to lessen the manual handling of raw material to address the sanitation problems of traditional fish paste making. The machine has a design capacity of 10.5 kilograms with the following parts and functions:

1) The support frame is made up of up of $1 \frac{1}{2} \times 1 \frac{1}{2}$ stainless tubular bars

2) The mixing chamber, 18" in length and 16" in diameter is made up of stainless sheet. Inside the mixing chamber is the vertical shaft with radial paddles that rotates centrally for the mixing process.

3) The vertical shaft with the fabricated paddle rotates during the mixing process. The vertical shaft is made up of a $3 / 4$ " stainless shaft connected to a $3 / 4$ " stainless round bar. It has $3 / 4$ flanged bearing attached to gear for rotation and conjoint to the dynamo of $1 \mathrm{hp}$.

4) At the lower end of the mixing chamber is the outlet chute and the conveyor made up of PVC pipe that receives material from the outlet chute.

5) The outlet chute is made up of a stainless sheet that is cylindrically shaped into 10 " height and 10 " diameter. At the lower end of the outlet, the chute is a removable cap made up of a 5" PVC Pipe. 


\section{DRAWINGS:}

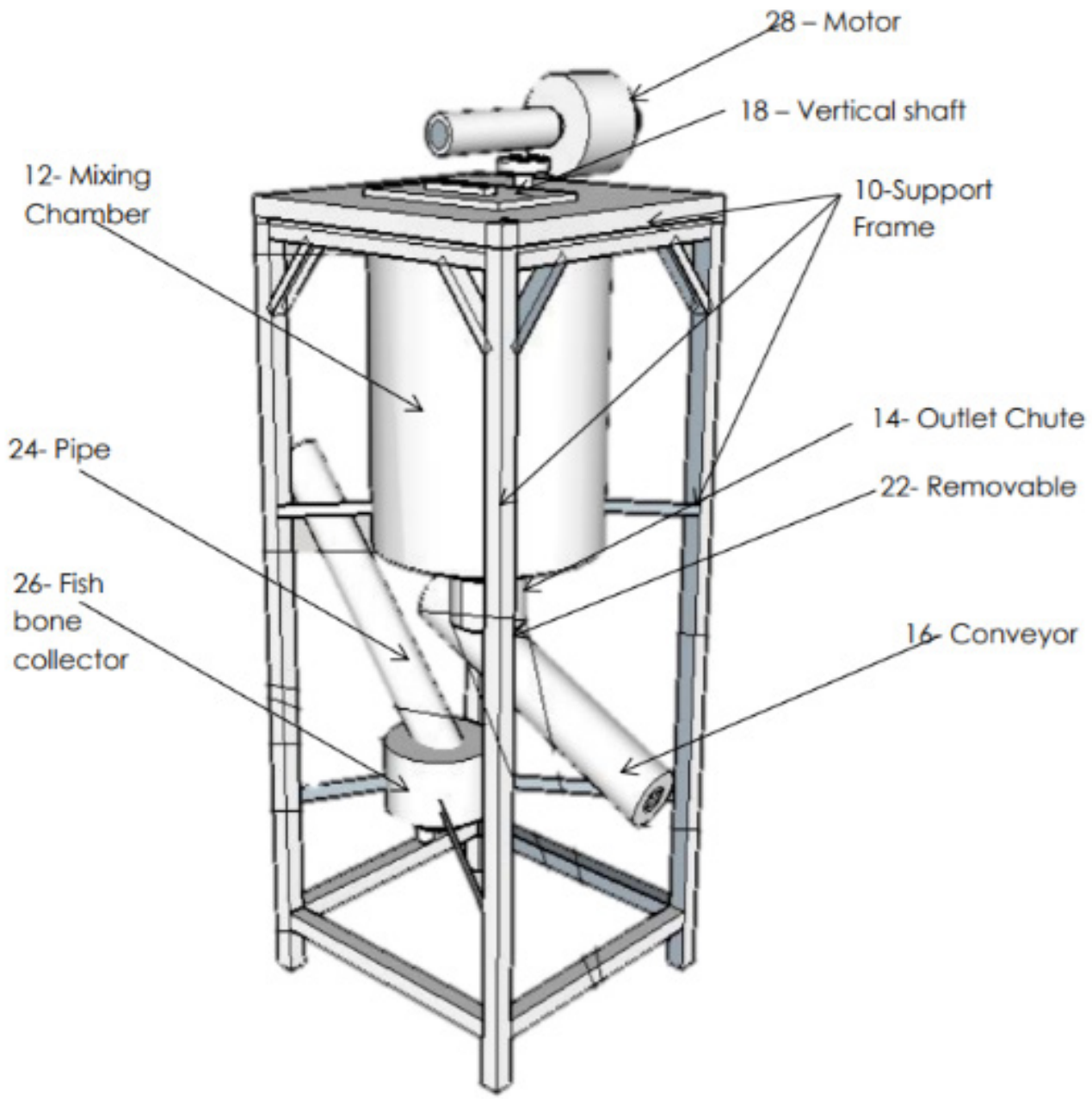

Figure 1. The Mechanized Fish Paste Maker

\subsection{Evaluation of the Product}

The product was first evaluated in terms of functionality, durability, aesthetics, and safety. Functionality refers to the usefulness and the ease of operating the developed prototype; durability refers to the stability and the robustness of the product; while aesthetics refers to the physical attributes of the product suited to its purpose, and safety refers to security of the users when using the product. Ten randomly selected fish paste makers and five fish paste producers in the municipality of San Jose, Occidental Mindoro, Philippines evaluated the developed product using three varieties of fish: "pampanger", anchovy, and mackerel tuna.

\subsection{Efficiency Rating of the Developed Product}

Since the developed product aims to lessen the manual labor and increase the efficiency of the fish paste process, a Time and Motion Study (TMS) between the traditional method and the developed product is conducted where each stage in the fish paste process from the time of handling the raw material to the finished products is observed and recorded. The number of bottled liquid fish paste was further compared to the outputs of the traditional process. The TMS aims to eliminate the unnecessary work and design the most effective methods and procedures to achieve a certain task. [11]. TMS provides techniques to analyze in detail an operation or task, measuring which activities add value and how to minimize and eliminate the ones that don't add value or are considered a waste. TMS in the manufacturing industry enables to calculate the capacity and increases efficiency and productivity, making the organization more competitive to the point thru lower production costs, offering a quality product at a lower price to the customer [12]. More importantly, TMS is one of the important methods of estimating machine changeover time and can depict the efficiency of a developed machine using the multi-linear regression model and multi-layer perceptions [13]. 
The study employed the TMS by measuring the standard time to perform a task using a stopwatch and work sampling. The traditional process has five job entries starting with the mixing of the salt and fish, transferring of mixed salt and fish to container, fermentation stage, transferring of fermented fish to container, and the bottling process. While there are 7 job entries used on the TMS of the developed machine: mixing of salt and fish, disengaging the pipe, transferring of the mixed salt and fish to container, fermentation, placing the fermented product in the mixer, straining process, and the bottling process. The normal time and standard time of performing the job entries were observed and recorded. Lastly, a cost-benefit analysis was conducted to determine the cost of savings incurred by the developed product against the traditional method.

\section{Results and Discussion}

\subsection{Testing Results}

The developed product was evaluated by ten fish paste makers and five fish paste producers in San Jose, Occidental Mindoro, Philippines. Three varieties of fish were mixed, fermented, and strained on the developed product. The functionality of the developed product refers to the usefulness and ease of operation with comfort and convenience obtained a mean score of 4.57 interpreted as "Very good". This means that the product is easily operated and manipulated with a minimum level of commands. In terms of durability which refers to the strength of the product in terms of materials and design obtained a mean score of 4.90, interpreted as "Very good" reflecting that the material and design are appropriate and suited for the intended purpose. While, the evaluation on the efficiency of the products in terms of conformance to the desired output and the absence of human works was rated 4.30 interpreted as "Very good", further describing that the product achieved the desired objective of lessening the manual operations and increasing the efficiency of the fish paste making. Lastly, the evaluation on the safety of the product obtained a mean score of 4.52, interpreted as "Very good" reflecting that the product is safe to use and could not harm the users during the operations. Table 1 shows the summary of the evaluation in the four criteria.

Table 1. Mean Score of Performance Evaluation

\begin{tabular}{ccc}
\hline Content & Mean & Interpretation \\
\hline Functionality & 4.57 & Excellent \\
Durability & 4.90 & Excellent \\
Efficiency & 4.30 & Excellent \\
Safety & 4.52 & Excellent \\
\hline Grand Mean & 4.57 & Excellent \\
\hline
\end{tabular}

Legend: 0.00-1.00-Poor; 1.01-2.00 Fair; 2.01-3.00-Good; 3.01-4.00 Very Good; 4.01-5.0: Excellent

The grand mean of 4.57 interpreted as "Excellent" reflects that the product met the intended function or purpose; the product design and materials are durable and suits the functionality of the product; is efficient and consistent in providing the ease of operation, and is safe to use during the fish paste preparation with safety features that could not harm the users and can guarantee a safe and clean fish paste.

\subsection{Performance Efficiency of the Product}

To further establish the efficiency of the developed product compared to the traditional method, the number of bottles produced against the time of operation involved in the fish paste making was observed and analyzed. This also aims to determine if the sizes of fish can affect the time of operation and the number of bottles produced. The time of operation starts when the salt and fish are mixed and other processes commence until the bottling process. Figure 1 shows the comparison of the time of operation involved in preparing the anchovies fish paste.

The figure significantly shows the advantages in terms of the time of operation involved in producing the three varieties of fish paste; the graph shows that a longer time is involved in the traditional method against the time of operation using the developed machine. The sizes of fish used in the fish paste do not affect the performance of the developed machine and significantly show more fish paste bottles are produced. 


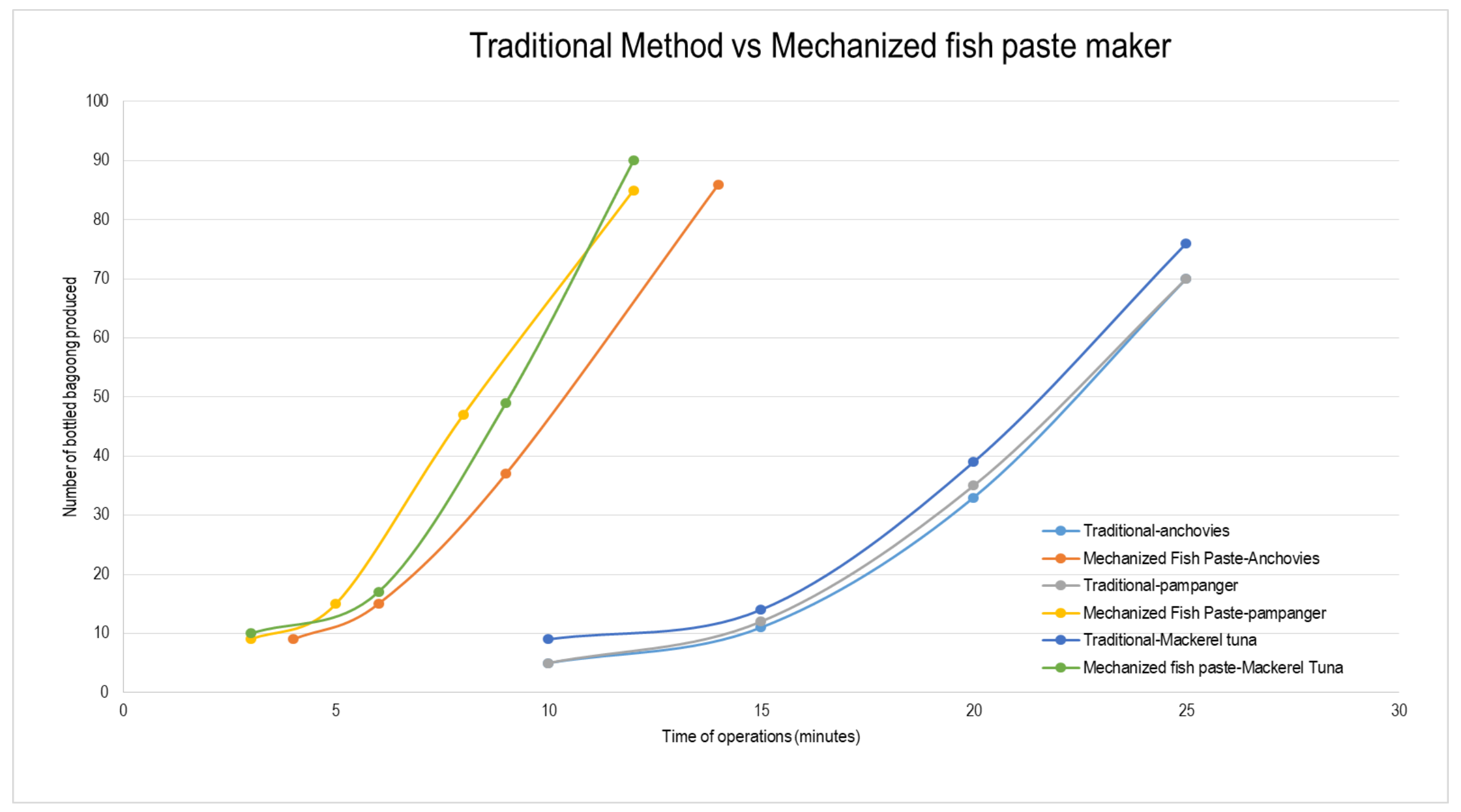

Figure 2. The number of bottles produced against the time of operations 
The normal and standard time of operation involved in the fish paste making was further analyzed using the time and motion study. Considering the five (5) job entries in the traditional method: mixing of salt and fish, transferring the mixed fish to container, fermentation, transferring the fermented fish in the bottling area, and the manual bottling of the fermented fish; and the seven (7) job entries in the developed machine: mixing of salt and fish, disengaging the pipe, transferring of the mixed salt and fish to container, fermentation, placing the fermented product in the mixer, straining process, and the bottling process, the researchers were able to present the advantages of using the developed machine. Normal time refers to the usual time to complete given job entries entailed in the traditional method without applying any engineering work methods. While the standard time refers to the time to complete the job entries using work management methods. Table 2 shows the summary of computed normal and standard time for anchovies.

The table reflects that in all weights of anchovies used, the mechanized fish paste maker consistently manifested more efficient performance than the traditional method in terms of standard time as it entails only 72 days with the use of the machine. With the computed production capacity of $52.43 \%$, a total of 57 days can be saved in the production process. Another trial was conducted between the traditional method and the developed machine using a medium size fish and Table 3 shows the TMS for "pampanger".

It can be viewed in Table 3 that the mechanized fish paste maker manifested a production capacity of $53.68 \%$ compared to the traditional method. Using the machine can reduce the duration of fish paste production by 56 days. In the normal time at mechanized fish paste maker, the fish paste can be produced even after 26 days. The results of the TMS consistently show how the developed machine can help the producers to reduce the production time and increase production. Lastly, a larger fish was used as the main ingredient in the fish paste making and Table 4 shows the TMS for mackerel tuna.

Table 2. Summary of TMS of Anchovies

\begin{tabular}{|c|c|c|c|c|c|c|c|c|c|}
\hline \multirow{3}{*}{$\begin{array}{l}\text { Weight of } \\
\text { pampanger } \\
\text { (kilograms) }\end{array}$} & \multicolumn{4}{|c|}{ Traditional Method } & \multicolumn{4}{|c|}{ Mechanized Fish paste Maker } & \multirow{3}{*}{$\begin{array}{c}(\%) \\
\text { Production } \\
\text { capacity }\end{array}$} \\
\hline & \multicolumn{2}{|c|}{ Normal Time } & \multicolumn{2}{|c|}{ Standard Time } & \multicolumn{2}{|c|}{ Normal Time } & \multicolumn{2}{|c|}{ Standard Time } & \\
\hline & sec & days & Sec & days & sec & days & sec & days & \\
\hline 2 & 6708342.65 & 78 & 7446260.34 & 86 & 2235741 & 26 & 2481673.00 & 29 & 33.72 \\
\hline 4 & 8938515.48 & 103 & 9921752.18 & 114 & 4471425 & 52 & 4963281.96 & 57 & 50.00 \\
\hline 6 & 11173649.42 & 129 & 12402750.85 & 144 & 6707360 & 78 & 7445169.75 & 86 & 59.72 \\
\hline 10.5 & 13409353.80 & 155 & 14884382.72 & 172 & 8938109 & 103 & 9921301.33 & 114 & 66.27 \\
\hline \multicolumn{4}{|c|}{ Average Standard Time } & 129 & \multicolumn{3}{|c|}{ Average Standard Time } & 72 & \\
\hline \multicolumn{9}{|c|}{ Average Production capacity } & 52.43 \\
\hline
\end{tabular}

Table 3. Summary of TMS for "pampanger"

\begin{tabular}{|c|c|c|c|c|c|c|c|c|c|}
\hline \multirow{3}{*}{$\begin{array}{l}\text { Weight of } \\
\text { pampanger } \\
\text { (kilograms) }\end{array}$} & \multicolumn{4}{|c|}{ Traditional Method } & \multicolumn{4}{|c|}{ Mechanized Fish paste Maker } & \multirow{3}{*}{$\begin{array}{c}(\%) \\
\text { Production } \\
\text { capacity }\end{array}$} \\
\hline & \multicolumn{2}{|c|}{ Normal Time } & \multicolumn{2}{|c|}{ Standard Time } & \multicolumn{2}{|c|}{ Normal Time } & \multicolumn{2}{|c|}{ Standard Time } & \\
\hline & sec & days & Sec & days & sec & days & sec & days & \\
\hline 2 & 6708395.18 & 78 & 7446318.65 & 86 & 22883.73 & 26 & 2540094 & 29 & 33.72 \\
\hline 4 & 11173318.10 & 103 & 9921697.95 & 115 & 4576616 & 53 & 5080044 & 59 & 51.30 \\
\hline 6 & 8938466.62 & 129 & 12402383.09 & 144 & 6865141 & 79 & 7620306 & 88 & 61.11 \\
\hline 10.5 & 13409194.68 & 155 & 14884206.09 & 172 & 9148359 & 106 & 10154679 & 118 & 68.60 \\
\hline \multicolumn{4}{|c|}{ Average Standard Time } & 129 & \multicolumn{3}{|c|}{ Average Standard Time } & 73 & \\
\hline \multicolumn{9}{|c|}{ Average Production capacity } & 53.68 \\
\hline
\end{tabular}


Table 4. Summary of TMS for mackerel tuna

\begin{tabular}{|c|c|c|c|c|c|c|c|c|c|}
\hline \multirow{3}{*}{$\begin{array}{c}\text { Weight of } \\
\text { Anchovies } \\
\text { (kilograms) }\end{array}$} & \multicolumn{4}{|c|}{ Traditional Method } & \multicolumn{4}{|c|}{ Mechanized Fish paste Maker } & \multirow{3}{*}{$\begin{array}{c}(\%) \\
\text { Production } \\
\text { capacity }\end{array}$} \\
\hline & \multicolumn{2}{|c|}{ Normal Time } & \multicolumn{2}{|c|}{ Standard Time } & \multicolumn{2}{|c|}{ Normal Time } & \multicolumn{2}{|c|}{ Standard Time } & \\
\hline & Sec & days & Sec & days & sec & days & sec & days & \\
\hline 2 & 9043480.11 & 105 & 10038262.92 & 116 & 2262183 & 26 & 2511023.3 & 29 & 25.00 \\
\hline 4 & 11304512.61 & 131 & 12548008.99 & 145 & 4524289 & 52 & 5021960.3 & 58 & 40.00 \\
\hline 6 & 13381164.78 & 155 & 13565935.08 & 157 & 6786499 & 79 & 7533013.7 & 87 & 55.41 \\
\hline 10.5 & 13381164.78 & 155 & 14853092.91 & 172 & 9043521 & 105 & 10038308 & 116 & 67.44 \\
\hline \multicolumn{4}{|c|}{ Average Standard Time } & 148 & \multicolumn{3}{|c|}{ Average Standard Time } & 73 & \\
\hline \multicolumn{9}{|c|}{ Average Production capacity } & 46.96 \\
\hline
\end{tabular}

Table 5. Cost-Benefit Analysis of Mechanized Fish Paste Maker against the Traditional method

\begin{tabular}{|c|c|c|c|c|c|}
\hline \multicolumn{4}{|c|}{ 1-month production (per fish tubs) } & Traditional & Mechanized \\
\hline Raw Materials & Quantity & Unit & Unit Price & \multicolumn{2}{|c|}{ Amount } \\
\hline Fish & 60 & kilograms & 60.00 & $3,600.00$ & $3,600.00$ \\
\hline salt & 1.5 & sack & 100.00 & 150.00 & 150.00 \\
\hline Operator & 1 & day & 300.00 & - & 300.00 \\
\hline Electricity & 1 & hour & 12.00 & - & 12.00 \\
\hline \multirow[t]{2}{*}{ Laborers } & 3 & day & 300.00 & 900.00 & - \\
\hline & & & & $4,650.00$ & $4,062.00$ \\
\hline 10 drums & 30 & fish tubs & & $139,500.00$ & $121,860.00$ \\
\hline 12-month production & & & & $1,674,000.00$ & $1,462,320.00$ \\
\hline \multirow{2}{*}{\multicolumn{4}{|c|}{ Mechanized Fish paste Maker (1 unit) }} & & $18,000.00$ \\
\hline & & & & $1,813,500.00$ & $1,480,320.00$ \\
\hline 10 drums & 1 & month & & \multicolumn{2}{|c|}{ Production } \\
\hline 10 drum & 20000 & bottles & 9.00 & $180,000.00$ & $180,000.00$ \\
\hline 12 month period & & & & $2,160,000.00$ & $2,160,000.00$ \\
\hline Profit & & & & $486,000.00$ & $679,680.00$ \\
\hline Investment & & & & $1,674,000.00$ & $1,480,320.00$ \\
\hline Return on Investment & & & & $29 \%$ & $46 \%$ \\
\hline
\end{tabular}

Table 4 shows that even with mackerel tuna, the machine is still productive compared with the traditional method. The average production capacity of $46.96 \%$ exhibited the effectiveness of the machine even if a large size of fish is used. However, it can be observed that 2 kilograms of mackerel tuna consumed 116 days in the traditional method; and much longer than the TMS computed for 2 kilograms of anchovies and "pampanger". This is attributed to the fermentation period of mackerel tuna that takes longer compared to small fishes. The production capacity of the developed machine with the three varieties of fish further proves its capability to increase the production profits; the shortest time of fermentation the better for the fish paste producers. Instead of almost 3 months of waiting before bottled fish paste can be marketed, the developed machine guaranteed that in one month, the bottled fish paste can be available.

\subsection{Cost-Benefit Analysis}

Since the product is to be introduced in the fish paste industry in the province, a cost-benefit analysis was added to attract possible investors and buyers and to establish the advantages of the product in terms of monetary value. The analysis included the cost of raw materials and the manual labor needed in the traditional methods against the initial cost of the developed machine. Table 5 shows the cost-benefit analysis considering one-month production.

The table shows the return on investment incurred by the traditional method and the mechanized fish paste maker. The computations are based on a fish tub having a capacity of 60 kilograms and on the average production of 10 drums per month. In the traditional method, the mixing of raw materials to the bottling process covers much of the production cost against the machine cost, operator, and electricity. The annual production cost was estimated and observed that a higher amount is entailed by the traditional method causing lower ROI. The table significantly shows that investing in the machine has a higher rate of optimizing the production operations and the profit.

\section{Conclusions}

The Mechanized Fish paste Maker is designed to lessen the manual operations in fish paste production by 
combining the mixing and straining process in one compartment. The materials used in the developed machine complied with the criteria set for functionality, durability, aesthetics, and safety. The overall efficiency rating of 4.57 reflects that the product met the intended function or purpose; has a durable design and materials suited to the functionality of the product; is efficient and consistent in providing ease of operation, and is safe to use. The performance efficiency rating of the machine has an overall rating of $51.02 \%$ than the traditional method of fish paste making. The TMS results also show that the developed machine can lessen the duration of fish paste production; that even in one month time period, the bottled fish paste can be produced. Thus, the works and operations of fish paste makers will be lessened. Moreover, the cost-benefit analysis also shows that the product can increase production as the lesser time of operation is involved and decreases the number of laborers needed. The computed ROI further proved that the use of the machine can increase the profit as more bottles of fish paste can be produced in lesser time.

\section{Acknowledgments}

We are very grateful to the Intellectual Property Office of the Philippines for the grant of Philippine Patent under Invention 1/2021/050326.

\section{REFERENCES}

[1] Bureau of Fisheries and Aquatic Resources. (2015). BFAR Report-Philippine Fisheries Profile. https://www.bfar.da.g ov.ph/files/img/photos/2015FisheriesProfile(Final).pdf.

[2] Philippine Statistics Authority. (2015). Quarterly commercial and municipal/inland fisheries surveys. (Accessed July 29, 2015).https://psa.gov.ph/content/philip pine-statistics-authority-conducts-quarterly-commercial-an d-municipalinland-fisheries.

[3] Guevarra, G. (1991). Fish Products Data Collection in the Philippines: A Personal Experience. Proceedings of the Seminar on Advances in Fishery Post-harvest technology in Southeast Asia: Singapore, May 6-11, 1991, pp. 296-300. http://repository.seafdec.org/bitstream/handle/20.500.1206 6/4804/GuevaraG1991.pdf? sequence $=1 \&$ isAllowed=y

[4] Arquillano, N.E. (2019). Profiling of Fish paste Production, Journal of Education, Management and Social Sciences, 2(1), 52-58. ISSN 2599-4670

[5] Agmata, A.B., Asis, A.M., Santos, M.D. (2013). Species identification of padas from fermented fish paste or bagoong using DNA barcode. Philippine Science Letters, 6 (2) https://www.philsciletters.net/2013/2013n2.24.pdf

[6] Bajet, M.A., Bajet, N.A., Bermio, J.B., Bajet-Paz, C.A., Bajet, J.B. (2012). Fish Paste Mechanized Squeezer". IAMURE International Journal of Mathematics, Engineering and Technology, 4(1) http://www.ejournals.p $\mathrm{h} /$ article.php? $\mathrm{id}=2800$

[7] Jayathilakan, K., Sultana, K., Radhakrishna, K., Bawa, A.S. (2012). Utilization of byproducts and waste materials from meat, poultry and fish processing industries: A review. Journal of Food Science Technology, 49 (3), 278-293. DOI: 10.1007/s13197-011-0290-7

[8] Hastings, S. (2005). Fish chum system and process for making same. United States Patent Application. Publication No.: US 6955006 B1, October 2005, https://patentimages.storage.googleapis.com/10/63/2c/ae0a fc5f3df4a7/US6955006.pdf

[9] Panjamadisorn. J., Kittisupakorn, P. (2010). Development of a Filling Sauce Equipment System for Fish Canning Industry. Proceedings of International Multi-Conference of Engineers and Computer Scientist, 3, March 17-19, 2010

http://www.iaeng.org/publication/IMECS2010/IMECS201 $0 \_$pp1749-1753.pdf

[10] Freeland, R.A (2013). Tuna Squeezer. United States Patent Application. Publication No.: US 2013/02201148A1, August 2013,https://patents.google.com/patent/US201302 20148A1/en

[11] Puvanasvaran, A.P., Mei, C.Z., V.A. Alagendran V.A. (2013). Overall Equipment Efficiency Improvement Using Time Study in an Aerospace Industry. Procedia Engineering, 68, 271 - 277. DOI:10.1016/j.proeng.2013.1 2.179

[12] Cury, P.H., Saraiva, J. (2018). Time and motion study applied to a production line of organic lenses in Manaus Industrial Hub. Gest. Prod., São Carlos, 25(4), 901-915. https://doi.org/10.1590/0104-530X2881-18

[13] Kutschenreiter-Praszkiewicz, I. (2018). Machine learning in SMED. Journal of Machine Engineering, 18(2), 31-40. https://doi.org/10.1590/0104-530X2881-18 